\title{
Determination of Kidney Length and Volume by Ultrasound in 100 Term Bangladeshi Newborn
}

\author{
SABINA SULTANA ${ }^{1}$, SHAFIQUR RAHMAN² ${ }^{2}$ BIPLOB KUMAR BASAK ${ }^{3}$, NILOFAR SHAMEEM AFZA ${ }^{4}$, \\ MD. NURUL HOSSAIN ${ }^{5}$, SARWAR FERDAUS ${ }^{6}$
}

\begin{abstract}
:
Objective: To determine the normal range of kidney length and volume in term Bangladeshi newborn.

Methods: Hundred inborn, healthy, appropriate for gestational ages, term infants were prospectively examined by sonography within 72 hours of birth by a single senior sonologist. In 52 boys and 48 girls body weight (BW), supine length (SL), occipito frontal circumference(OFC) were collected from delivery room records, and body surface area (BSA) was calculated using the formula $B S A=B W(\mathrm{~kg})^{0.425} \times B L(\mathrm{~cm})^{0.725}$ $\times 0.007184$ and $B M I=W e i g h t(k g) / h e i g h t(m)^{2}$. Scanning was performed with $6.5 \mathrm{MHZ}$ transducer with child supine position. Maximum length of each kidney was determined. Volume of the kidney was determined by the inbuilt formula of software. Kidney length and volume were then correlated with gestational age, body weight, length, OFC, body mass index (BMI) and body surface area of infant.

Results: There were no significant differences in mean kidney length and volume between right $(39.22 \pm 4.32 \mathrm{~mm}, 9.79 \pm 2.80 \mathrm{cc})$ and left $(38.36 \pm 4.30 \mathrm{~mm}, 9.82 \pm 2.24 \mathrm{cc})$ and kidneys in boys (right kidney $39.77 \pm 4.28 \mathrm{~mm}, 10.30 \pm 2.69 \mathrm{cc}$, left kidney38.62 $\pm 3.68 \mathrm{~mm}, 9.91 \pm 2.06 \mathrm{cc}$ ) and girls (right kidney $38.63 \pm 4.32 \mathrm{~mm}$, $9.23 \pm 2.83 \mathrm{cc}$ left kidney $38.09 \pm 4.91 \mathrm{~mm}, 9.73 \pm 2.43 \mathrm{cc})$. Kidney length was correlated better with $B M I(<0.001), B W(<0.01)$ and BSA. $(<0.05)$. Kidney volume was also correlated with $B W(<0.05), B M I(<0.05)$ and BSA $(<0.05)$. No correlation found with length and OFC.
\end{abstract}

Conclusion: The present study provides an important baseline data in term babies for kidney dimension in Bangladeshi neonate.

Key words: Neonate, kidney length, kidney volume, ultrasound.

\section{Introduction:}

Ultrasound is an important imaging modality for renal tract in children and during the last few years ultrasound has been increasingly used for evaluating kidney anatomy in neonatal period. It is well tolerated and does not involve the use of ionizing radiation or

1. Associate Professor of Paediatrics, Uttara Adhunik Medical College Hospital, Dhaka, Bangladesh

2. Principal and Head of the Department Of Radiology and Imaging, Uttara Adhunik Medical College Hospital, Dhaka, Bangladesh.

3. Junior Consultant of Paediatrics, Uttara Adhunik Medical College Hospital, Dhaka, Bangladesh

4. Associate Professor of Gynae and Obs, Uttara Adhunik Medical College Hospital, Dhaka, Bangladesh

5. Assistant Professor of Paediatrics, Uttara Adhunik Medical College Hospital, Dhaka, Bangladesh

6. Professor and Head of the Department of Paediatrics, Uttara Adhunik Medical College Hospital, Dhaka, Bangladesh

Correspondence: Dr. Sabina Sultana, Email: sultanasm20 @yahoo.com intravenous contrast medium ${ }^{1}$. In the newborn and infants, ultrasound is useful for follow up in prenatally detected fetalhydronephrosis ${ }^{2,3}$ and suspected renal tract malformation. In older children, kidney sonography a part of the work-up for urinary tract infection, enuresis, dieresis or flank masses ${ }^{1}$. Other indication include, suspicion of obstructive uropathy, ambiguous genitalia, renal failure, localization for renal biopsy. Descriptions of the ultrasound diagnosis of renal vein thrombosis and adrenal haemorrhage in the neonate have been reported ${ }^{4,5}$. It is also well known that changes in kidney dimensions may precede renal echotexure changes in certain renal disease.

There are reports of some studies on kidney sizes in neonate among Caucasians $\mathrm{S}^{6,7,8}$ and Asians $^{9}$. However, reports of similar studies are scant in our country. So, the rationale for this study is to determine 
the normal range of renal length and volume in apparently healthy term Bangladeshi neonates by ultrasonography. This study would also facilitate to compare the values with other countries for any, racial differences in term neonatal kidney size.

\section{Patients and Methods:}

The study was done during the period of of March 2007 to December 2010, In uttara Adhunik medical college. Consecutive 100 full term inborn, 52 boys and 48 girls, with gestational age from completed 37 weeks to 41 weeks (mean $39.06 \pm 1.071$ week) and birth weight from $2 \mathrm{~kg}$ to $4 \mathrm{~kg}$ (mean $2.98 \pm 0.374 \mathrm{~kg}$ ) were studied.Infants with malformations or other serious diseases and maternal history of oligohydramnion were excluded. Gestational age was determined by maternal dates and Dubowits assessment ${ }^{10}$. The birth weight, length and occipitofrontalcircumference (OFC) of each baby were recorded. Body surface area (BSA) was calculated using the formula $B S A=B W(\mathrm{~kg})$ $0.425 \times \mathrm{BL}(\mathrm{cm}) 0.725 \times 0.007184$ andBMI $=$ weight $(\mathrm{kg})$ lheight $(\mathrm{m})^{2}$. Sonography was done by a single senior sinologist was done by a single senior sinologist within 72 hours of birth. A real time ultrasound Scanner with a $6.5 \mathrm{MHz}$ was used. The baby was scanned while held in caretakers/mothers lap or across the shoulder. Scanning was done in both supine and prone positions. Each kidney was examined in its longitudinal axis from which the bipolar length and width were measured in millimetres $(\mathrm{mm})$. A third transversely oriented measurement was taken to obtain antero-posterior diameter or thickness. The ultrasound machine automatically calculated the volume $(\mathrm{cm} 3)$ by inbuilt formula of software. Data handling and statistics was done using SPSS software. Continuous variables were expressed as a mean \pm standarddeviation (SD). Students t-test paired unpaired observation), pearson correlation test was used where appropriate. The kidney length and volume were calculated for both kidneys. The measured values were then correlated with birth weight, body length (height), OFC and BMI. A p value of $<0.05$ was considered significant.

Permission for the examination was always sought from at least one parent, who was given an explanation both verbally and in writing- of the purpose of the study, the technique to be used and the steps that would be taken if anything abnormal was found.

\section{Results:}

Three babies were excluded from the analysis, one had solitary kidneys, one had solitary pelvic kidney and one had a horse shoe kidney. A total 100 neonates were studied, which comprised 52 boys $(52 \%)$ and 48 girls (48\%). The right kidney (mean right kidney length) was found to be slightly longer than the left $(39.22 \pm 4.32 \mathrm{~mm}$ VS. $38.36 \pm 4.30 \mathrm{~mm})$. The difference was however statistically not significant. The volume of right and left kidney were almost same $(9.79 \pm 2.80 \mathrm{cc}$ VS 9.82 $\pm 2.24 \mathrm{cc}$ ) (Table-I).

Table-I

Kidney length and volume in the term infants $(n=100)$

\begin{tabular}{lccc}
\hline & Right & Left & $P$ \\
\hline Variables & kidney & kidney & value \\
Length $(\mathrm{mm})$ & $39.22 \pm 4.32$ & $38.36 \pm 4.30$ & $>0.50^{\text {ns }}$ \\
Volume $(\mathrm{cc})$ & $9.79 \pm 2.80$ & $9.82 \pm 2.24$ & $>0.50^{\text {ns }}$ \\
\hline
\end{tabular}

The length and volume of right and left kidney between the boys and girl were also not significantly different (Table-II). As there was no significant difference found, the dimensions of all 200 kidneys were measured as a single group. Six independent variables were used (gestational age, Birth weight, infant length, Infant OFC, BMI and BSA) to correlate with two dependent variable kidney length and kidney volume. Table-III, shows kidney length correlated better with BMI (<0.001), BW (<0.01) and BSA (<0.05). No correlation was found with gestational age, length with OFC. Table-IV shows kidney volume was correlated with BW $(<0.05)$, BMI $(<0.05)$ and BSA $(<0.05)$. Here also no correlation was found with gestational age, length and OFC.

Table-II

Kidney length and volume in term boys and girls

\begin{tabular}{lccc}
\hline $\begin{array}{l}\text { Variables } \\
\text { Length }(\mathrm{mm})\end{array}$ & $\begin{array}{c}\text { Boys } \\
(\mathrm{n}=52)\end{array}$ & $\begin{array}{c}\text { Girls } \\
(\mathrm{n}=48)\end{array}$ & $\begin{array}{c}\mathrm{P} \\
\text { value }\end{array}$ \\
\hline Right kidney & $39.77 \pm 4.28$ & $38.63 \pm 4.32$ & $>0.10^{\mathrm{ns}}$ \\
Left kidney & $38.62 \pm 3.68$ & $38.09 \pm 4.91$ & $>0.10^{\mathrm{ns}}$ \\
Volume $(\mathrm{cc})$ & & & \\
Right kidney & $10.30 \pm 2.69$ & $9.23 \pm 2.83$ & $>0.05^{\mathrm{ns}}$ \\
Left kidney & $9.91 \pm 2.06$ & $9.73 \pm 2.43$ & $>0.50^{\mathrm{ns}}$ \\
\hline
\end{tabular}


Table-III

Correlations of the infant kidney length with different parameters of mothers and term infants $(n=100)$

\begin{tabular}{lcc}
\hline Parameters & Correlation & P value \\
\hline Gestational age & 0.050 & $>0.50^{\mathrm{ns}}$ \\
Infants body weight & +0.257 & $<0.01^{* *}$ \\
Infants height & +0.085 & $>0.10^{\mathrm{ns}}$ \\
Infants OFC & +0.165 & $>0.10^{\mathrm{ns}}$ \\
Infants BMI & +0.316 & $<0.001^{* * *}$ \\
Infants BSA & +0.223 & $<0.05^{*}$ \\
\hline
\end{tabular}

Pearson correlation, ns $=$ not significant ${ }^{*}{ }^{* *}=$ significant $\mathrm{BMI}=$ Body mass index, $\mathrm{BSA}=$ Body surface area, $\mathrm{OFC}=$ Occipitofrontanl circumference

Table-IV

Correlations of the infant kidney volume with different parameters of mothers and term infants $(n=100)$

\begin{tabular}{lcc}
\hline Parameters & Correlation & P value \\
\hline Gestational age & +0.115 & $>0.10^{\text {ns }}$ \\
Infants body weight & +0.226 & $<0.05^{*}$ \\
Infants height & +0.185 & $>0.05^{\text {ns }}$ \\
Infants OFC & 0.000 & $>0.50^{\text {ns }}$ \\
Infants BMI & +0.205 & $<0.05^{*}$ \\
Infants BSA & +0.227 & $<0.05^{*}$ \\
\hline
\end{tabular}

Pearson correlation, ns = not significant * = significant, $\mathrm{BMI}=$ Body mass index, $\mathrm{BSA}=$ Body surface area, $\mathrm{OFC}=$ Occipito frontal circumference

\section{Discussion}

Ultrasound is preferred to urography for assessment of kidney size as it is free of radiographic magnification and contrast induced increase in kidney size associated with later ${ }^{11,12}$. The use of ultrasound in the neonatal period is also advantageous because it can be performed at the bed side. Certain conditions are known to affect kidney size without much affecting renal echotexure. Examples of such conditions include Beckwith-Wiedmann syndrome, renal vein thrombosis and infant of diabetic mothers ${ }^{13,14,15}$. Studies on kidney size in neonate are abundant in literature, but this cannot be true in our environment $8,16,17,18$. In our study length $(\mathrm{mm})$ of right and left kidney was found $39.22 \pm 4.32$ and $38.36 \pm 4.30 \mathrm{~mm}$ respectively which is some what lower than the study of Mesrobian and coworkers ${ }^{8}$, Adeyekunn and co- worker ${ }^{19}$. There was no difference of data between the sexes. Lotus and others made a similar observation of the independence of renal length of gender in their study conducted 0 Chinese children ${ }^{9}$, Komus and colleagues ${ }^{20}$, in their study on Turkish children and Adeyekum and colleagues also noted a similar trend, in Nigerian children ${ }^{19}$. The volume of kidney was also some what lowers than the others data which was $10 \mathrm{cc}^{21}$ in comparisons to 9.79 to $9.82 \mathrm{cc}$ in our series, but due to scanty information about the volume of term baby. We could not compare with many. In this study neonatal kidney length was better correlated with infant $\mathrm{BMI}(<0.001)$ than body weight $(<0.01)$ and body surface area $(<0.05)$ but in the study of AK Gupta and Colleague $^{22}$ renal dimension was correlated best with the body surface area and gestational age, rather than birth weight, but they included both preterm and term baby in their series. We did not find any correlation with gestational age.

Adeykun $\mathrm{AA}$ and collegue ${ }^{19}$ showed significant correlation with renal length and renal volume with neonatal weight and length. Here also we could not find any correlation with infant length. Fitzsimons $\mathrm{RB}^{23}$ also found significant correlation between kidney length and birth weight. He did not compare with other variables.

\section{Conclusion:}

The present study provides an important baseline data in term babies for kidney dimension in Bangladeshi neonate as well as neonate. BMI, BSA both are correlated with kidney length and volume, along with Body weight, so other two can also be selected as the independent variables for preparation of normogram for normal standard of Kidney length and kidney Volume in term infant.

\section{References:}

1. Reid BS.Pediatric abdominal sonography. In: Kawamura DM(ed). Diagnostic medical sonography- a guide to clinical practice, Philadelphia Lippincott: 1997:601-26.

2. DocimoSG, Silver RI. Renal ultrasonography in newborn with prenatally detected hydronephrosis; Why wait? J urol 1997; 157: 1387-9.

3. Laing Fc, Burke VD, Wing VW, et al. Post partum evaluation of fetal hydronephrosis: optimal timing 
for follow up sonography. Radiology 1984:152:423-4.

4. Lawson EE, Teele R.L. Diagnosis of adrenal haemorrhage by ultrasound. J pediar 1978:92:423-6.

5. Rosenberg ER, Trought WS, Kinks Dr, sumnerTE, Grossman H. Ultrasound diagnosis of renal vein thrombosis in neonate. AJR 1980;134:35-8.

6. Dinkel E, Entel M, Dittrich M. Kidney size in childhood sonographic growth charts for kidney length and volume. PediartrRadiol 1995, 15:3843.

7. Currarino G, Willims B, Dana K. Kidney length correlated with age: normal values in children. Radiology 1984; 150: 703-4.

8. Mesrobian Hg, Laud PW, ToddE, Gregg DC. The normal kidney growth rate during year 1 of life is variable and age dependent. J Urol 1998; 160(3): 899-93.

9. Lotus Wk, Gent RJ. Le Quesne GW, Metreweli C. Renal length in Chinese children; Sonographic measurement and Comparison with western data. J clin Ultrasound 1998; 26(7): 249-52.

10. Scott JE, Hunter EW, Lee RE, Mattews JN. Ultrasound measurement of renal size in newborn infants. Arch Dis child. 1990 apr; 65(4 spec No): 361-4. Pubmed PMID:2186707; pubmed central PMCID: Pmci590153.

11. Emamian SA, Nielsen MB, Pederson JF ytte L. kidney dimensions at sonography: Correlation with age, sex, and habitus in 665 adult volunteers, Am J Roentgenol 1993;160:83-6.

12. OditaJc, Ugbodaga $\mathrm{Cl}$. Roentgenologic estimation of Kidney size in adult Nigerians. Trop geogr Med 1942;34:177-81.
13. Naeye RL. Infants of diabetic mothers: a quantitative morphologic study. Paediatrics 1965 , 35:980-2.

14. Kissane JM. The Kidney. In: pathology of Infancy and childhood , $2^{\text {nd }}$ edn, Ed Kissane JM. St Louis, CV Mosby, 1975, p 624.

15. Mc Carter KM. Cleveland RH,Simeone JF, Aretz T. Renal ultrasonography in Beck withWeidmann syndrome. PediatrRadiol 1981, 11:46.

16. Currarino G, Williams B, Dana K. Kidney length correlated with age: Normal values in children. Radiology 1984; 150:703-4.

17. Rosenbaum DM, Korngold E, Teele RL. Sonographic assessment of renal length in normal children. AJRAm J Roentgenol 1984; 142; 467-9.

18. Han BK, Babcock DR. Sonographic measurement and appearance of normal kidney in children. AJR Am J Roentgenol 1985; 145: 611-6.

19. Adeyekun AA, IbadinMO, Omoigberale AI Ultrasound assessment of Renal size in healthy term neonates; A report from Benin City, Nigeria, Saudi J Kidney Dis Transplant 2007; 18(2): 27781.

20. Konus OL, OZdemir A, AKKaya A, et al. Normal liver, spleen and kidney dimensions in neonates, infants and children; evaluation with songraphy. AJR Am J Roentgenol 1998; 171(6): 1693-8.

21. Holloway $H$, Jones TB, Robinson AR, Harpen $\mathrm{MD}$. Wiseman $\mathrm{Hj}$. Sonographic determination of renal volumes in norlam neonates. Paediatric radiol; 1983; 13(4): 212-4.

22. A.K Gupta, N.KAnand, IMS, Lamba. Ultrasound evaluation of kidney dimension in neonate. Indian paediatrics. Volume 30, March 1993; 319-24.

23. Fitzsimons RB. Kidney length in the newborn measured by ultrasound. Acta paediatric sound, 1983; 72(6): 885-7. 